\title{
Duties of Group Agents and Group Members
}

DOI:

10.1111/josp. 12181

\section{Document Version}

Accepted author manuscript

Link to publication record in Manchester Research Explorer

\section{Citation for published version (APA):}

Collins, S. (2017). Duties of Group Agents and Group Members. Journal of Social Philosophy. https://doi.org/10.1111/josp.12181

\section{Published in:}

Journal of Social Philosophy

\section{Citing this paper}

Please note that where the full-text provided on Manchester Research Explorer is the Author Accepted Manuscript or Proof version this may differ from the final Published version. If citing, it is advised that you check and use the publisher's definitive version.

\section{General rights}

Copyright and moral rights for the publications made accessible in the Research Explorer are retained by the authors and/or other copyright owners and it is a condition of accessing publications that users recognise and abide by the legal requirements associated with these rights.

\section{Takedown policy}

If you believe that this document breaches copyright please refer to the University of Manchester's Takedown Procedures [http://man.ac.uk/04Y6Bo] or contact uml.scholarlycommunications@manchester.ac.uk providing relevant details, so we can investigate your claim.

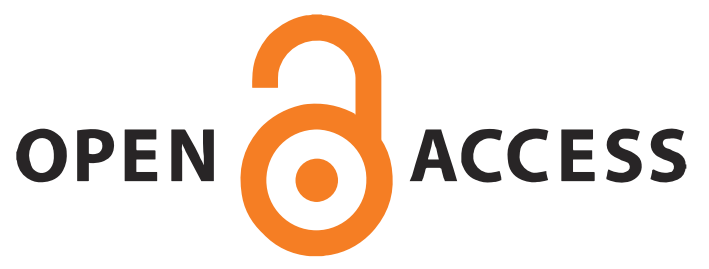




\title{
Duties of Group Agents and Group Members ${ }^{1}$
}

\author{
Stephanie Collins, University of Manchester \\ This is the final draft of a paper whose definitive version will be published in \\ Journal of Social Philosophy
}

\section{Introduction}

'Starbucks has a duty to ensure its coffee growers receive a decent wage.' 'Médecins Sans Frontières has a duty to operate in Syria.' 'The US has a duty to take the lead on climate change mitigation.' These are assertions about the duties of group agents. This article aims to answer two questions about such duties. First, are group agents' duties identical to a collection of individual duties? Second, if a group agent fails to do its duty, does this imply that at least one member has failed to do their duty?

These two questions are obviously related. It may seem natural to pair the answers to each: one might 'yes' to both, and thereby be an individualist about group duties; or one might answer 'no' or both, and thereby be a holist about group duties. This article aims to take a middle path between these poles, by answering 'no' to the first question - arguing instead that group agents' duties are distinct from a collection of individual duties - while answering 'yes' to the second - arguing that if a group agent fails to fulfil its duty, then a member will have failed to fulfil an individual-level duty somewhere along the way. If these answers are correct, they give us good reason to pay attention to both the group-level and the individual-level in our ascriptions of duties, and of blame for failures to fulfil them.

\footnotetext{
${ }^{1}$ For helpful comments and discussions, I thank Alex Barber, Jonathan Farrell, Joseph Kisolo-Ssonko, Holly Lawford-Smith, Thomas Smith, two anonymous reviewers, and participants at a workshop on "Collective Obligation" at the University of Manchester.
} 
After $\S 1$ characterises the group agents with which the argument is concerned, §2-4 address the first of the two questions. I will introduce the idea that, when a group agent has a duty, at least some individuals have duties in virtue of being members. These are 'membership duties.' I argue for a particular characterisation of membership duties (§2). In order to demonstrate the wide and varied extent of membership duties, §3 describes three ways in which members can fail to fulfil them. This will play the role of conceding as much as possible to a particular individualist answer to the first question, that is, that a group agent's duty is identical to a collection of membership duties. After all, the more wideranging membership duties are, the better are their prospects for crowding group agents' duties out of our ontology.

Yet group agents' duties are not identical to a collection of membership duties. I will argue that group agents can do something that their members-taken either severally or in aggregate - cannot do: reliably produce multilateralism (coordinated performance of roles) amongst members. The duty to produce multilateralism is distinct from a collection of membership duties (§4). We should therefore answer 'no' to the first question above.

If the duty to produce multilateralism is irreducibly group-level, then (one might think) failures to fulfil that duty might be possible without individual-level failure. On the contrary, $\S 5$ argues that if a group fails to discharge its duty to produce multilateralism, then a member will also have failed to discharge a membership duty, at some point or other. This answer to the second question diverges from the growing consensus that groups can be blameworthy even when no individual member is blameworthy (List and Pettit 2011, ch. 7; Lawford-Smith 2012, 465-7; Pettit 2007, 195-6; Smith 2009, 50-54). ${ }^{2}$ In sum, while the early

${ }^{2}$ Copp $(2007 ; 2012)$ argues for a slightly different claim: that it is conceptually and morally possible that a collective has an all-things-considered duty to do X while members have only pro tanto duties to do their part in X. He may be correct about this. In contrast, my focus is on 
sections will argue that we should not focus on individual duties alone, the last section will argue that we should never be content to focus on group duties alone. In contexts with group agents, both levels are important.

\section{Group Agents}

In line with other theorists of group responsibility, I assume the mark of agency is rational decision-making (French 1984; List and Pettit 2011; Pettit 2007; Rovane 1998). A procedure for rational decision-making allows an entity to move from desire-like and belief-like inputs to decision-like outputs, in a way that maintains rough coherence across its desires, beliefs, and decisions from different times and in different domains. This is a functionalist account of agency.

A group can bear agency in this sense, by having a group-level rationally operated decision-making procedure. ${ }^{3}$ Such a procedure takes in beliefs and desires of members, and/or beliefs and desires of the group (as established by earlier decisions of the group). The group then reasons about these in a way that, first, maintains coherence with other beliefs and desires of the group and, second, is likely to be distinct from how any member reasons about her own beliefs and desires. To see the distinctness, consider that the group might use majoritarian, deliberative, or consensus rules to reasons about its inputs. These are probably not the methods used by a member when deciding for herself. By operating its procedure in a way that maintains rational coherence, the group will produce decisions, some of which might be of the form "the group will perform action X." When the procedure produces outputs of demonstrating that a group's (all-things-considered or pro tanto) failure implies at least pro tanto failure of members. This is consistent with, but different from, Copp's claim.

${ }^{3}$ Peter French $(1979,211)$ calls the group procedures "corporate internal decision structures," while Christian List and Philip Pettit (2011, esp. 48) call them "aggregation functions." 
this decision-to-act kind, it will also usually distribute roles to members that are jointly sufficient for the performance of X.

In order to operate its procedure rationally, a group must orient its small-scale and short-term goals around large-scale and long-term goals, and must achieve rough coherence between its various beliefs and desires at a given time. To do this, the group will reason, that is, it will entertain its beliefs and desires as objects - have 'meta-propositional beliefs' about them, in Pettit's terms (2007b). By entertaining its beliefs and desires as objects, a group holds a number of such objects in its attention at once, and asks itself about the relations between those objects: support, consistency, entailment, coherence, and so on. I will assume (though I have not defended) that such meta-propositional reasoning is required to be an agent.

To further motivate the idea that groups can be agents, consider that a group can use its old beliefs, desires, and decisions to reason towards new beliefs, desires, and decisionssome of which its members may not predict (Pauer-Studer 2014, 1629-1630). In doing this, the group may well (if it satisfies some minimal criteria, like non-dictatorship) come to believe, desire, and decide things that none of its members believe, desire, or would decide. This allows the group's agency to escape the control of the members, in favour of control by the past states of the group itself (List and Pettit 2011, ch. 2; Pettit 2007a, 181-6; Pettit 2007b). I will assume - though it is not uncontentious - that all of this gives us sufficient reason to believe some groups are agents. ${ }^{4}$

\footnotetext{
${ }^{4}$ I thank an anonymous review for pressing the importance of meta-propositional beliefs.

Pauer-Studer (2014) argues that the functional account of agency (which I assumed above) cannot account for the meta-propositional beliefs that enable reasoning about, and justification for, decisions. However, it seems possible that principles of instrumental rationality (which the functional account assumes), combined with general and long-term
} 
Moreover, I'll assume group agents can be moral agents. After all, if a group's members are human moral agents, and can recognise moral reasons, then it is natural to assume they can design a group decision-making procedure so that moral reasons are treated as desires, in the sense of having a 'world-to-mind' direction of fit. And it is natural to assume they can design the procedure so that the group, by and large, responds to moral reasons, such that the group takes its own measures in response to these reasons (Pettit 2007, 187). Of course, it's unlikely that the group will do this infallibly, but if infallibility were the standard for moral agency, then no human would be a moral agent. So, assuming (as I will) that duties are moral reasons with high or presumptive force, groups can bear and discharge duties.

\section{Memberships Duties}

With these conceptual assumptions in place, we can turn to the first question posed in the introduction: are group agents' duties identical to a collection of individual duties? In this section, the aim is to give a full characterisation of the individual duties to which group

desires that have weighty or trumping value for the group (which the functional account accommodates), is enough for meta-propositional beliefs to arise via a functionalist story. I will therefore assume - with the literature cited above - that the functional account is sufficient for agency, though, again, this permissiveness is not uncontested

By contrast and more permissively, some authors believe that non-agent groups can bear duties (Wringe 2016) or that individuals can bear obligations that are shared (Björnsson 2014) or joint (Schwenkenbecher 2013). I leave such possibilities to one side, focusing on obligations of group agents, in the sense just outlined, held by them singly (not jointly or shared with other agents). 
agents' duties might be identical. By being expansive in this characterisation, the idea is to concede as much as possible to a 'yes' answer to this question. That answer will then be challenged in $\S 4$.

So, when a group agent has a duty, what duties do its members have (in virtue of being members)? Call these individual-level duties 'membership duties.' What's their broad structure?

This question is not merely asking about the duties that the members have contracted into with the group, or have as officially designated roles. It's also — at least potentiallyasking about what they should do beyond those contracted or designated roles. For example, we can ask: if my university has a moral duty to divest from fossil fuels, then what does this require of me, morally speaking? If we simply read the answer off my contractual or designated roles, the answer is 'nothing': nothing in my contractual or designated roles can reasonably be interpreted as having anything to do with the university divesting from fossil fuels. Yet something might be morally required of me on the back of my university's duty, even if I have no explicit role that relates to this duty (indeed, even if my university refuses to acknowledge that it has this duty). Plausibly, if my university has a duty to divest from fossil fuels, then-because I am a member-I have a (pro tanto) duty to use my position within the university to push the university in this direction, whether it instructs me to or not. Our conception of membership duties should at least allow for this possibility. Again, the idea here is to concede as much as possible to the individualist.

This clarification of the question requires us to forgo the initially promising idea that, when a group has a duty, "individuals are required to fulfil the responsibilities of their respective roles within the organization. ... To the extent that they perform the duties associated with the respective roles, they are doing their part in relation to the collective obligation." (Isaacs 2011, 132-3) We should allow that particular duties of the group might 
require members to act beyond their prescribed roles, at least in some cases and when much is morally at stake. Membership duties, then, are not merely duties to perform one's prescribed role. They are more targetted-to-a-particular-group-duty than this.

In any case, as Isaacs notes, the initially promising answer is dangerously underdescribed (ibid.). Roles are often very loosely defined. The demands of the role 'Prime Minister,' for example, are open to numerous interpretations. This ambiguity in roles' content is particularly problematic when it comes to playing one's part in the group's duties, since more latitude in one's role generally correlates with more power over the group's fulfilment of its duties. Thus, those individuals who have the most power over the fulfilment of the group's duty tend to have the least determinacy about what 'performing their role' consists of. For these individuals at least, the relevant individual duty cannot simply be a duty to "perform your role'-even if the designated duties of the role can be interpreted as relevant to the particular duty of the group. The role-bearer needs more guidance than simply 'be Prime Minister.' So the answer to our question is, first, more relevant to each group duty, and second, more specific, than simply 'members have duties to perform their roles.'

That said, a member's role is related to her membership duties. To see this, imagine my university has a moral duty to divest from fossil fuels. Imagine that the university won't divest unless its nearby competitor does, and that I'm best-placed to convince the competitor: I could promise its vice-chancellor that, if her university divests, I'll take down my university from the inside by getting terrible student ratings. Maybe divestment is so important that I have a duty to make - and keep - this promise. But this duty doesn't look like a duty-quamember. This is because the duty is a duty to positively renege on my role within the university (specifically, my role of providing good teaching). A duty-qua-member should have the member, in some sense, cohering with the group agent itself. (Again, this is not to say that duties not-qua-member don't trump membership duties.) What's more, the 
university's divestment duty could imply a (pro tanto) competitor-convincing duty for my equally best-placed neighbour, who is not a member of either university. (This is assuming that, in general, individuals can have pro tanto duties to make it more likely that other agents will do their duty.) My neighbour's duty would not be a duty-as-university-member, since she is not a university member.

This suggests that, if I have a duty in virtue of my membership, then the duty must at least be one that I can use my role in the group to discharge. This implies that I have such a role (unlike my neighbour). We should thus be discontent with another possibility, namely that group duties imply duties for members to "do their part as appropriate in bringing it about that the collectives to which they belong meet their duties." (Copp 2012, 84). "As appropriate" covers a multitude of actions, not all of which are me using my role, so not all of which are explained by my membership, so not all of which are my duty as a group member.

These initial points suggest the following. If a group has a duty to see to it that $\mathrm{X}$, then each member has, because they are a member, a duty to use their role, as appropriate, with a view to seeing to it that $\mathrm{X}^{5}$ These members' duties are (i) relevant to the particular group duty (since "seeing to it that $\mathrm{X}$ " is mentioned in the content of the duty), (ii) not too vague (again, since $\mathrm{X}$ is mentioned), and (iii) dependent on the member's role in the group. The 'as appropriate' clause implies that, for some members, this duty will involve simply checking that there's no action they need to take.

\footnotetext{
${ }^{5}$ The "see to it that" locution follows Pettit and Goodin $(1986,654)$, who assume that duties take the form "A is called upon to see, so far as possible, that- $p$," where $p$ might be that A "does something; that another specified individual does something; that something is done, no matter by whom; or that something simply is the case." That is, the formulation covers the full range of agent-relative and action-orientated—rather than outcome-orientated—duties.
} 
One might wonder whether group agents' duties really entail these duties: what if a group has a duty to see to it that $\mathrm{X}$, but no member has a role that they can use with a view to seeing to it that X? For example, imagine Médecins Sans Frontières simply had no procedures in place for operating during the Syrian war. It's then doubtful that any member could use their role with a view to operating in Syria. But we wouldn't want to deny that the group has the duty. In such a case, I suggest, the group's duty to operate in Syria transmutes into a duty to create roles that can be performed with a view to operating in Syria. This group duty straightforwardly implies member duties: duties for members to use their roles to put certain beliefs and desires on the group's decision-making agenda, with a view to distributing roles that, if used appropriately, would be sufficient for the group's operating in Syria.

Of course, 'sufficient for' does not mean 'absolutely guarantors of' - after all, events might unfold, completely beyond the group's control, which make it impossible for the group to discharge its duty. Instead, 'sufficient' here means 'sufficient in a high proportion of the ways the future is likely to be.' Just how 'high' a 'high proportion' is will vary, depending on the importance of the group's duty.

All of this suggests the following:

If a group has a duty to see to it that $\mathrm{X}$, then

1. Each member has a duty to use their role, as appropriate, to put inputs into the group's decision-making procedure with a view to the procedure's distributing roles to members in a way that: if enough members used their roles with a view to seeing to it that $\mathrm{X}$, then that would be sufficient for $\mathrm{X}$ in a high proportion of likely futures. These are 'X-sufficient' roles. 
But the mere distribution of X-sufficient roles is not enough. It must also be that members actually do their bit. So:

If a group has a duty to see to it that $\mathrm{X}$, then

2. Once X-sufficient roles are distributed, then each member has a duty to use their role, as appropriate, with a view to seeing to it that $\mathrm{X}$.

Call (1) and (2) 'membership duties.' They are described here at a very general level, particularly with regard to demandingness. Just how much cost a member must take on in discharging his membership duties will depend on how his membership duty weighs up against other duties he has-including membership duties he has because of other duties of the group, membership duties he has because of his membership in other duty-bearing groups, and duties he has as a moral agent in his own right. We can acknowledge that a multitude of actions are included within the pro tanto membership duty he acquires on the basis of the group's duty, while acknowledging that this membership duty might be outweighed or overridden.

\section{Failure to Discharge Membership Duties}

This section will demonstrate that membership duties can require diverse and wide-ranging actions. There are two reasons for demonstrating this: first, because it grants as much as possible to the individualist, who claims that group agents' duties are nothing more than a collection of membership duties. Denying this kind of individualism is one of the two aims of the paper. The more expansive membership duties are, the easier it is to hold this kind of individualism, and so the harder $\S 4$ 's rebuttal of individualism becomes (and the more significant, should the rebuttal succeed). A second reason for demonstrating the diversity and 
breadth of membership duties is that it will allow me to establish the paper's other main claim (in $\S 5$ ): that a failure to fulfil a group-level duty entails a failure to fulfil a membership duty.

To demonstrate the breadth and diversity, I'll outline three (quite different) ways in which failures to fulfil membership duties might cause a group agent to renege on its duty.

First and most obviously, one or more members might negligently or maliciously fail to discharge their membership duties - either by failing to put inputs into the procedure with a view to the procedure's distributing roles jointly sufficient for X, or by failing to use their role with a view to seeing to it that $\mathrm{X}$. This is a violation of a membership duty for all and only those members who fail in this way.

A second type of membership duty failure occurs when those who set up the group, or who provided the inputs when the procedure was used to distribute roles, did not set up the procedure or provide the role-distributing inputs in ways that safeguarded against individuals' negligence or malice, resulting in group failure. The individuals who set up, or gave inputs for, the procedure might have failed to distribute "back-up" roles, or failed to install sufficient checks and balances. They might have failed to recruit enough members to fulfil all of the group's duties, or failed to distribute roles evenly enough among members. These actions could all be part of membership duties, and these people have not done all that they should to use their roles with a view to the group's fulfilment of its duties. These people have reneged on a membership duty. This failure of membership duties might end up being attributed to, inter alia, the group's founders, as individuals.

Of course, it would be overly-demanding to say that these founders had membership duties to include some universally competent sub-unit or governance structure that permits the group to adapt to any new circumstances appropriately. ${ }^{6}$ Where this is true, and where the lack of such procedures results in group failure, we are unable to attribute violations of

\footnotetext{
${ }^{6}$ I thank Alex Barber for pressing this.
} 
membership duties to individuals. In $\S 5$, I consider whether the group has nonetheless reneged on a duty in these instances.

Third and most complicatedly, individuals' fulfilment of their membership duties might be undermined by their false yet reasonable beliefs. Again, this kind of membership duty failure can result in group duty failure. Unlike the first two types, however, there is no pro tanto individual blameworthiness for this type of membership duty failure. For example, suppose Starbucks has a duty to ensure its coffee growers receive a decent wage. Consider Sam, a Starbucks executive, who reasonably believes that even if she does her part, other members will not do theirs. If Sam acts in accordance with her role with a view to decent wages for growers, then (she reasonably believes) this will be futile. Sam's performance of her membership duty is thwarted by the fact that she reasonably believes fulfilling it would be pointless.

There are two ways in which Sam might reasonably believe her duty is pointless. In the way I just described, Sam reasonably believes that the group duty that her duty helps to fulfil — the duty to ensure growers have decent wages — would not be achieved even if she did her duty. In this case, her fulfilling her duty is reasonably believed to be futile. Sam would also reasonably believe her duty to be pointless if she reasonably believed that the group's duty would be fulfilled whether or not she did her membership duty. For example, suppose Sam reasonably believes that Ellie the Starbucks executive is going to try to take on the entire decent wage duty herself, whether or not Sam plays her part. Suppose Ellie is known by Sam to be very competent. Sam knows that Ellie will almost certainly succeed on her own. In this case, Sam reasonably believes that the group's aim will be achieved whether or not she does her duty. Here, Sam's performance of her duty is reasonably believed to be superfluous.

Reasonable beliefs in futility or superfluity are two types of reasonable beliefs in pointlessness. Crucially, though, these reasonable beliefs might be false. Suppose that, in the 
futility belief case, the others would have done their bits if Sam had done hers. In the superfluity belief case, suppose Ellie was not actually going to attempt the group's duty alone. If so, Sam has failed to discharge an membership duty, which leads to group-level failure to discharge its duty. This is a failure or violation on Sam's part, even though she is not blameworthy for it. Perhaps various members are blameworthy for not distributing the roles in a way that was sensitive to Sam's reasonable beliefs (a failure of type two). However, if such duties would be overly demanding, then even this won't be correct. Instead, there will be membership failure, and group failure, without membership blameworthiness.

Holly Lawford-Smith $(2012,462)$ makes a similar point about how reasonable beliefs can blamelessly impede members from doing their bit. However, according to LawfordSmith, each member's duty just is 'do your bit in the group's duty or reasonably believe doing so would be pointless.' This formulation implies that the reasonable-yet-false belief in pointlessness can be used to discharge the membership duty, as opposed to being used merely to remove one's blameworthiness for not discharging the membership duty. This will matter in §5: her formulation leads Lawford-Smith to state that the individuals can each do their duties - perhaps by forming reasonable-yet-false beliefs - without the group doing its duty (ibid.). I will disagree with her on this, and our disagreement on the present point explains why.

Why agree with me rather than Lawford-Smith? Why believe the duty is 'do your bit', with reasonable-yet-false beliefs-in-pointlessness playing an excusing, rather than a dutyfulfilling, role? Because this is how it typically works in other moral contexts: if I fail to save a drowning toddler, we typically don't think I've fully done my duty if I reasonably-yetfalsely believed that I would drown if I tried to save him. My belief excuses me from blame, but there is a moral remainder. This moral remainder is my objective (as opposed to 
subjectively believed) duty, which I have failed to discharge. So it is, I'm suggesting, for membership duties.

I press this in order to demonstrate that membership duties are tenacious. If one can fail in them simply by having reasonable-yet-false beliefs, this implies that, across a wide range of circumstances, members will have failed in their membership duties. This is concessive to the individualist: it will make it more difficult for me to show (in §4) that group duties are anything more than a collection of membership duties.

There are yet more opportunities for failure of membership duties. So far, I have described three 'first-order' failure types. When any of these occur, this might (though will not necessarily) trigger 'second-order' duties for the group (i.e., duties arising from failures in other duties), which imply second-order membership duties, with the potential for further failures at this second level. These second-order failings are a third potential source of blameworthiness for individuals. For example, suppose Starbucks fails in its duty in one of the three ways just described. Often (not necessarily always), Starbucks will have a new, second-order duty to remedy this. If so, this will generate new, second-order membership duties for Sam.

These second-order membership duties might include: duties to communicate anger, disappointment, surprise, shame, or frustration at herself or other members; duties to distance herself from the mistake (or own up to it, as the case may be); duties to work to change the ethos or procedures of the group; and so on. If the first-order duty failure was of type three, then Sam's second-order duties might be to find out whose beliefs were faulty, in order to ensure they are discharging their general epistemic duties; or to use her role to set up systems that guard against such reasonable-but-false beliefs in the future. 
These second-order duties do not rely on the blameworthiness of Sam or anyone else. They are triggered simply by the fact that there was group failure. ${ }^{7}$ And if Sam does not fulfil her second-order membership duties, then she will be blameworthy for that (unless she reasonably believes her fulfilling these second-order duties would be pointless, or unless the duties were outweighed by other more weighty duties, or so on). As with first-order duties, these second-order membership duties might, all-things-considered, be overridden, outweighed, or constrained by various other moral or non-moral demands on Sam. But even in large groups, individuals often have a high chance of making a small difference —or a low chance of making a large difference — to the way the group responds to failure. ${ }^{8}$ These can lead to pro tanto membership duties.

Membership duties can thus require a wide and diverse range of actions. However, there is more to group duties than a collection of membership duties.

7 Isaacs $(2011$, pp. 77, 79) similarly points out that individuals can sometimes have obligations to "distance" themselves from groups they belong to as a result of group failings, even if the individuals are not blameworthy for anything.

${ }^{8}$ Zoller (2014) equates group blameworthiness with the blameworthiness of members with “steering power." By contrast, my analysis doesn't distinguish steering from non-steering members (this is surely a difference in degree rather than kind), and doesn't hold any members blameworthy for the group failure as such (because steering members rarely have the entire group under their thumb). This is not to deny that members with more steering power will likely have a higher degree of blameworthiness than members with less steering power, when both members fail to discharge their membership duties. 


\section{Groups' Capacities to Reliably Produce Multilateralism}

This section will argue that groups often have capacities to perform actions or realise outcomes that are not identical to any collection of individual-level capacities. Thus, the duties to exercise these capacities are not identical to any collection of individual-level duties.

As a simple example, suppose a complicated beach rescue can be performed only by a team of lifeguards. ${ }^{9}$ We can suppose the team is a group agent: its own long-term and overarching goal is to keep swimmers safe (by contrast, no member has this as his or her longterm and over-arching life-goal), and the team pursues this goal by updating its beliefs and (shorter-term) desires as a result of deliberation among members (by contrast, no member systemically deliberates with the other members when pursuing her over-arching life-goals); and coherence among beliefs and desires of the group takes precedence over perfectly tracking the current beliefs and desires of current members. In other words, the team has its own distinct and rationally-operated decision-making procedure.

The complicated rescue consists of a number of complementary (i.e., dissimilar) roles, which must be distributed and timed in just the right way. Because the roles are of this nature, only the group-level decision-making procedure can distribute the roles. If the lifeguards acted without prior team-level reasoning on the distribution of roles, the rescue would almost surely fail. This is not to say the team must sit down to a lengthy deliberation once the need for rescue becomes apparent. Instead, it is to say that the rescue will be successful only if team-level deliberation has already occurred, resulting in a clear division of roles to be enacted when complicated rescues arise.

The point is that the capacities of the lifeguards when there is no group-level decisionmaking procedure are not the same as the capacity that arises when there is such a procedure: the same individuals, if they were acting without the team's reasoning, do not have capacities

\footnotetext{
${ }^{9}$ A similar case is described in Collins 2013.
} 
that can be aggregated into a capacity to perform the complicated rescue. The non-agent group cannot be attributed this capacity, since it is insufficiently likely to perform the rescue, even if the individuals try. This is because they lack information about which parts the others are likely to play, and so about which part they should play. Group-level reasoning is required to distribute the parts, and thus for individuals to have sufficient information to do their bit in the rescue. Thus, the existence of a group agent brings a distinct capacity into existence: the capacity to perform the complicated rescue. ${ }^{10}$

This group-level capacity can be construed as the capacity to reliably produce multilateralism (coordinated role-performance) among members. The group's capacity to reliably produce multilateralism in pursuit of its actions is analogous to my capacity to reliably produce multilateralism in the parts of myself to run $10 \mathrm{~km}$. My legs are capable of moving the right way, my lungs are capable of breathing the right way, and so on. But these parts cannot reliably produce multilateralism amongst themselves unless they are coordinated by me. This coordinating capacity means that only I can reliably produce the multilateralism. The analogous capacity of group agents is to reliably generate multilateral (i.e., coordinated) role performance (fetching the boat, directing the boat, etc) among members.

Why attribute this capacity to the group, rather than the members? Because the group has "structural control" over its exercise. As Strand $(2012,216)$ explains it, "[s]tructural control works by ensuring the existence of mechanisms that ... control for the action by affecting the robustness of the bringing about of the action." That is, the group-level reasoning procedures ensure there are mechanisms (e.g., back-up roles, intra-group accountability, oversight, etc) in place, where those mechanisms ensure that, across a range of possible futures, some member or other will do certain things (fetch the boat and so on).

\footnotetext{
${ }^{10} \mathrm{I}$ am assuming here that 'A can $\mathrm{X}$ ' implies 'A is sufficiently likely to $\mathrm{X}$, given that $\mathrm{A}$ tries to $X^{\prime}$ '. A similar analysis of ' $\varphi$ is feasible for A' is in Brennan and Southwood (2007).
} 
Of course, the mechanisms do not 'ensure' with $100 \%$ certainty. All or most members might renege, and the group cannot absolutely ensure they don't. But the group does ensure against a fair amount of individual reneging, and this is sufficient for control. In general, to say I have 'control' over something (like my lifting of a cup), we don't require that thing occurs (or not) at my will in all possibly eventualities (for example, when we say I have control over my lifting of the cup, we don't require that the cup-lifting occurs at my will even if there is an earthquake or if my hand goes numb). To say I control for lifting a cup is just to say that, by and large in normal conditions, it's up to me whether or not it happens. This is level of control is sufficient for me to have a duty to lift the cup. The same is true for control exercised by groups: the group is not a perfect controller of any outcome, but it controls for some outcomes by-and-large.

When I say the group 'structurally' controls for an outcome, I mean that the group usually cannot determine that this or that exact member will do this or that in pursuit of the outcome, since each member can usually control what he or she does (as emphasised by Mäkelä 2007, esp. pp. 464-5). But the group 'structurally controls' that this or that will be done: the lifeguard team controls for the fact that, if Sandra does not drag the boat to the water, then Sandy will. It controls for the dragging of the boat, even if it doesn't control for which of Sandra or Sandy will do the dragging. Control over a generally-described phenomena-without control over which specific way in which the phenomena appears-is structural control. (See relatedly List and Menzies 2009; Jackson and Pettit 1990; Jackson and Pettit 1992.)

If it's true that the group agent's capacity to reliably perform the rescue is different from lifeguards' respective individual capacities to do various bits in the rescue (which seems so, since the latter exists without the former if there is no group agent), then it seems the action of exercising this capacity is not the same as the collection of actions that is each 
member doing their bit. If groups' capacities and actions are thus distinct from their members' capacities and actions - and if, as I will assume, structural control is sufficient control for bearing duties - then it seems plausible that groups' duties (to exercise structural control) are distinct from their members' duties (to play their part in or under such control).

This is all neutral on the metaphysical relation between a group's duty and its members' duties, for example the relations of supervenience, coincidence, constitution, grounding, and emergence. ${ }^{11}$ Distinctness does, however, rule out the view that the group duty is reducible to membership duties. By 'reductionism', I mean the view that "[e]very particular object [e.g., group's duty] in our social ontology is identical to ('the same as') some object [e.g., individual duty or set of individual duties] in the individual-level ontology. (There is at most a difference in description.)",12

If one agrees that group agents control events (e.g., the production of multilateralism) that members do not control, then there are two reasons to reject reductionism about group duties. First, the group's duty has explanatory power (see likewise Wringe (2016) on nonagent groups). The group's duty explains why membership duties arise: they arise to discharge the group's duty, which is a duty to exercise a capacity that only the group can control. The group's duty also explains why we should not view certain individuals' duties as membership duties: those individuals are not members of the group that has the group duty. My neighbour might have duties that arise out of my university's duty to divest from fossil fuels, but her fulfilment of those individual-level duties would not partly constitute (or compose, or cause, etc) the fulfilment of any duty of the university. If the group's duty

${ }^{11}$ There are huge literatures on each of these. See Tahko and Lowe (2015); McLaughlin and Bennett (2014); Bliss and Trogdon (2016).

${ }^{12}$ List and Spiekermann 2013, 633. This is one of four kinds of reductionism they outline, but is the most pertinent here. 
explains individual duties in these two ways, then we should resist saying it is identical to a collection of individual duties.

Second, we should resist reductionism because structural control implies that groups' duties are multiply realisable in individuals' duties, and therefore not identical to any one realisation. Take my university's duty to divest. This duty persists despite members joining and leaving. Such changes entail changes in how many membership duties there are, who has them, and what actions they require. This means the university's duty is realised in different ways at the level of membership duties, at different times. Yet each realisation is a realisation of one overarching duty, which belongs to the university rather than its members, and over which the university has structural control. (Multiple realisability is likewise stressed by List and Spiekermann 2013.)

The upshot of this section is the following: although membership duties can have a wide and varied range of content (as explained in \$2-3), groups' duties are not just a collection of individual duties. This is because groups can do things that members (taken severally or in aggregate) cannot do. Specifically, groups can structurally control for the exercise of the capacity to reliably produce multilateralism.

If group duties are not identical to a collection of individual duties, one might naturally think the following: if a group fails to do its duty, then perhaps no member has failed to do her duty. In the next section, I put pressure on this thought.

\section{The Implications of Group Failure}

So far, I have suggested that (a) pro tanto membership duties (and the ways in which individuals can fail to discharge them) are wide-ranging in their demands, and that (b) groups have duties over things that members do not (specifically, reliable production of multilateralism). This raises many questions about the relation between groups' duties and 
membership duties. One is: when a group fails to discharge a duty, does a member always fail too?

Given my characterisation of the capacity to reliably produce multilateralism, it might seem the answer is 'no.' On the contrary, I will appeal to membership duties-and, more specifically, the kinds of failure outlined in $\S 3$ - to challenge two types of cases, each of which suggest a group can fail to discharge a duty, without any member failing to discharge a duty (Pettit 2007a; Smith 2009). My argument here is non-deductive, but it nonetheless provides reason to believe that there is failure of membership duties whenever there is failure of group duties.

Again, my suggestion is not that the group's duty is reducible to the members' duties. $\S 4$ explains why. My suggestion is simply that when there is a violation at the group level, there is also a violation at the member level. My suggestion is also not that members failed to do exactly what the group failed to do-again, $\$ 4$ implies that groups' and members' duties really are over different things. My suggestion is rather that, if the group fails, then a member has failed to discharge a pro tanto membership duty, which is distinct from the group's duty. Additionally, I am not asserting that members are necessarily blameworthy for their failure: reasonable beliefs in pointlessness lead to blameless membership failure. Similarly, an individual is (I assume) not blameworthy if they perform some non-membership duty (say, a duty to a family member) that outweighs their membership duty. But this would be a failure to discharge a membership duty, nonetheless.

As a final clarification, I am concerned with failure rather than treatment-as-havingfailed. There might be pragmatic reasons for treating groups as if they have failed, while at the same time not treating members as if they have failed. But these reasons would not be that the group really has failed while the members really have not. Likewise, List and Pettit (2011, 156) usefully distinguish between holding someone responsible for their conduct and 
regulating their conduct. Perhaps we should regulate groups without (intentionally) regulating members, but not so for holding them responsible.

\subsection{Discursive Dilemma Cases}

Discursive dilemmas are the first crop of cases that suggest group failure without membership failure. Suppose A votes $(P \&(Q \& \sim R))$, B votes $(P \&(\sim Q \& R))$, and $C$ votes $(\sim P \&(Q \& R))$, so, by voting on each of $\mathrm{P}, \mathrm{Q}$, and $\mathrm{R}$ in turn, the group comes to believe $(\mathrm{P} \&(\mathrm{Q} \& \mathrm{R})) .{ }^{13}$ Suppose the belief that $(\mathrm{P} \&(\mathrm{Q} \& \mathrm{R}))$ leads the group rationally to hold a morally abhorrent belief, which leads the group to perform a morally abhorrent action, which it had a duty not to perform. It might seem that no individual is responsible for this belief of the group —after all, they each individually deny that $(\mathrm{P} \&(\mathrm{Q} \& \mathrm{R}))$ - so we must place blameworthiness the group itself (Pettit 2007a, 197-8).

Building on these cases, Pettit maintains that "it is possible to have a situation in which there is ground for holding the group agent responsible ... but not the same ground for holding individual enactors responsible. The responsibility of enactors may leave a deficit in the accounting books..." (2007a, 194) The deficit arises "so far as they are blamelessly ignorant of any harm that is collectively done; reasonably believe that they won't make a difference to the harm done, or at least not the right sort of difference; and act under a sense of duress or pressure from others." Furthermore, Pettit asserts, "there is always likely to be a shortfall in enactor responsibility..." (2007a, 196, emphasis added) The upshot is that a group can fail to discharge a duty, even while no member has failed to discharge membership duties.

${ }^{13}$ The discursive dilemma is a generalisation of the doctrinal paradox (Kornhauser and Sager 1993). The dilemma is discussed by Pettit and by List in many places, but especially List and Pettit 2011, ch. 2. 
My argument against this builds on Frank Hindriks (2009). Let us make (P\&(Q\&R)) more concrete: $\mathrm{P}$ is that humans are not sentient, $\mathrm{Q}$ is that humans are nutritious, and $\mathrm{R}$ is that humans are a sustainable food source. Assume these are each necessary and together sufficient for it to be permissible to kill and eat humans. The group comes to believe this, and to act on that belief. These beliefs and (even if not those beliefs, then) actions violate duties of the group.

We should ask: where have things gone wrong? The group's belief that $\mathrm{P}$ seems the crucial objectionable point. But why does the group believe P? In part, because both A and C voted for P. Why did A and C vote for P? Either it's because they voted as they didn't believe (in which case, assuming the group's duty is to aim at truth, they violated a membership duty to vote as they believed) or because they believed that P. Suppose it's the latter. Why did they believe that P? Again, either because they didn't deliberate appropriately with regard to reasons for and against $\mathrm{P}$ (in which case, they violated a membership duty to deliberate appropriately) or because they did deliberate appropriately, but nonetheless somehow fell into false beliefs about humans, which led to them violating a duty. ${ }^{14}$

Again, suppose the latter is true. Here, A and C have done their membership duty, which amounted to something like deliberate appropriately given the evidence, and vote accordingly. It might thus seem that the group has committed a violation (by believing that it's permissible to kill and eat humans) — without $\mathrm{A}, \mathrm{B}$, or $\mathrm{C}$ committing a violation. If $\mathrm{A}$ and $\mathrm{C}$ did all that was reasonable but nonetheless fell into false beliefs, then we can think of them each as having been in a constrained deliberative situation. However, if so, the group can appeal to this as constraining the group's deliberative situation, such that it was unable to believe as would have been ideal. After all, if the group is blamed for its abhorrent belief, it

\footnotetext{
${ }^{14}$ Hindriks reaches the same conclusion as me on the former case, but doesn't consider the latter case or the objections raised in the subsequent paragraphs.
} 
can reasonably defend itself: "Two members were highly constrained in their deliberations which bore on this decision. The group was therefore unable to believe as would have been ideal. The group's duty to thus believe (and to act accordingly) was blocked by oughtimplies-can.”

That is, the possibility of sound individual-level deliberation is a precondition for the group having a duty not to reach the morally non-abhorrent belief. So, the failure of individual-level deliberation removes the group's duty to avoid this belief. Rather than just implying that the group is non-blameworthy for not discharging the duty, the impossibility of sound individual-level deliberation implies the group's duty cannot arise in the first place. To see this, consider an analogy: suppose it would be highly valuable if I ran $100 \mathrm{~km}$ today. My lungs are simply incapable of sustaining such a long run now, and cannot be trained to do so in such a short time-span. Have I failed to discharge my duty to run $100 \mathrm{~km}$ ? Or does that duty never arise in the first place? I conjecture the latter. If a property of a part (or parts) is a genuine precondition for the whole being minimally able to perform some action, and that part-property is impossible, then the whole cannot have a duty to perform the action.

So, if $\mathrm{A}$ and $\mathrm{C}$ were in constrained deliberative situations, then the group doesn't fail to discharge a duty: the group's duty does not arise to begin with. It's therefore not a case of group failure without membership failure.

One might respond as follows: A's and C's constrained deliberative situations will not stop the group's duty from arising, if the group made it the case that $\mathrm{A}$ and $\mathrm{C}$ were in constrained deliberative situations. However, we can then iterate the previous few paragraphs' reasoning, with regard to the group decision that resulted in constraints on A's and C's deliberative situations. We can ask: how did the group come to constrain A and C's deliberative situations? Which individual inputs, beliefs, reasons, and epistemic situations feed into the group decision(s) that constrained A's and C's deliberative situations? Either the 
group is blameworthy for constraining $\mathrm{A}$ and $\mathrm{C}$, in which case members (possibly including $\mathrm{A}$ and $\mathrm{C}$ themselves) have violated membership duties relating to this constraining; or members have excuses (such as beliefs in futility or superfluity, as discussed in $\S 3$ ), in which case these excuses block the group-level duty (the duty not to constrain) from arising in the first place.

This account of the relation between group failure and member failure builds directly on $§ 3$ 's account of the ways in which membership duties can fail. That is, there are three options: either $\mathrm{A}$ and $\mathrm{C}$ violated duties by voting, believing, or deliberating as they did (a type-one failure); or the group's founders (or present-day leaders) violated duties by constraining A's and C's deliberative situations when A and C were deciding how to vote (a type-two failure); or members' using the procedure to constrain A's and C's situations was driven by a reasonable but false belief in the futility or superfluity of members trying to do otherwise (a type-three failure), in which case these beliefs block the group's duty (the duty not to believe it's permissible to kill humans) from arising at all, via ought-implies-can.

This might seem morally unsatisfying: how can the group have no duty against cannibalism? Surely it has such a duty. This is where $\S 3$ 's second-order duties become important. There are second-order membership duties to try to adapt the current decisionmaking procedure, disband the group entirely, or change the identities of individual members so that cannibalism doesn't occur. We need not appeal to the group's — or anyone else'sfailure of a past duty in order to make sense of imperatives to do such things. These imperatives derive simply from the goodness of stopping the group's terrible actions. Both members and non-members might have duties to react to group failure in this way, even though none of them-nor the group itself-are blameworthy for the fact that the group should be thus overhauled. 
All of that said, one might reply as follows: Pettit's more general point is that group members might be "blamelessly ignorant of any harm that is collectively done; reasonably believe that they won't make a difference to the harm done, or at least not the right sort of difference; and act under a sense of duress or pressure from others." $(2007 \mathrm{a}, 196)$ The cases of blameless ignorance, and of reasonable belief in futility, are covered by foregoing discussion. However, the idea of duress or pressure remains. This has close affinities with a second round of cases, which comes from Thomas Smith. I will now turn to these.

\subsection{Intra-group Mistrust Cases}

Smith draws on the following example from Frank Jackson: "There is a steady stream of traffic going to work. Everyone is driving at $80 \ldots$ It would be safer if everyone was driving at $60 \ldots$ But [of] each person ... if he or she were to drive at 60 , everyone else would still drive at 80, and so a lot of dangerous overtaking would result." (Jackson 1987, 102) Jackson's conclusion is that the group is blameworthy for driving at 80 , while the individuals are not. Smith agrees. Even supposing each driver has an overriding desire to produce road safety, still: perhaps "each drives at 80 because he believes that the others will do so and [given his desire for road safety] he reasonably prefers to drive at the same speed as them." (Smith 2009, 34-5) Are Jackson and Smith correct that here we have group-level failure without individual-level failure?

One way to posit individual-level failure in this case is to say that each driver has a duty to signal to the others her willingness to drive at 60 . To allow for this, Smith imagines the drivers have ten minutes in which they can use an intercom system to talk to each other. Even once the intercom system is introduced, Smith argues, group-level failure without individual-level violation could occur, if "every driver believes, and as their evidence indicates, were the drivers to thus [use the intercom to] commit to all drive at 60 , none would 
believe that the others will drive at $60 . "(2009,44)$ That is, "by stipulation, each driver would just know, perhaps by induction, or by some magical means, that their commitment has no evidential worth." $(2009,45)$ Each is excused by the untrustworthiness of others. Thus, Smith suggests, the group has done wrong by not signalling willingness to drive at 60 , while no individual has.

The group Smith considers is not an agent, and that may do some work in making the case plausible. But there are analogous cases where the group is an agent. Imagine, then, that the drivers constitute (or compose, or ground, or...) a group agent: suppose they are drivers for a delivery company. The case is then readily amenable to $\S 4$ 's characterisation: the group can and should produce multilateralism among members (i.e., all members driving at 60), and the individuals can do their bits in this, but they cannot all do so without group-level reasoning. It looks like the group has failed to produce multilateralism, without an individual failure.

However, a natural reaction is to hold the company's founders or managers responsible for the lack of intra-company trustworthiness, which meant each driver had good reason not to trust the others' commitments to drive at 60 . In $\S 3$ 's terms, this would be a failure of type two: managers or founders failed to install checks and balances that ensure that members were mutually trustworthy and trustful. This doesn't seem to ask too much of the managers or founders: intra-group trustworthiness and trustfulness is a general-purpose good, which the group's managers and founders are almost certainly blameworthy for not instilling in their company's culture.

It may be unlikely, but it's possible: suppose the managers or founders really could not have discharged their membership duties to instil intra-group trust, or perhaps those duties were so demanding as to be blocked from arising in the first place. Even then, I suggest, this is not a case of group-level failure without individual-level failure. For if the founders had no 
duties to instil trust, then this blocks the group's duty to drive at 60 via ought-implies-can, in the manner outlined in $\S 5.1$. That is, if the managers/founders were unable to instil intragroup trust, then the present-day group is being asked to do something it cannot do, because the preconditions for it doing that thing (where those preconditions were beyond the group's control) have not been met.

In sum, when we see group violation of a duty, we should ask three things: Did members deliberate, vote, lead, follow, or otherwise act in a way that failed to use their role with a view to discharging the group's duty (thereby violating a membership duty)? Did the founders or subsequent managers set up faulty procedures, back-ups, checks, balances, oversight, or otherwise fail to use their role to distribute roles that could be used to discharge the group's duty (thereby violating a membership duty)? Or, did reasonable, though false, beliefs of members prevent the members from doing their membership duties, thereby preventing the group from being able to do as it ought (thereby preventing the group's duty from arising at all)? Via discussion of discursive dilemma cases and intra-group trust cases, I have suggested that the answer to at least one of these questions will be 'yes.' I have not proven that no other counterexamples exist, but I do not know what form these might take.

\section{Conclusion}

Are group duties identical to a collection of individual duties? I have suggested that they do imply a collection of individual duties ('membership duties'), which have a particular structure and a wide range of content. I outlined three ways in which members can fail to fulfil their membership duties, two of which imply blameworthiness. My account of these duties builds upon other authors' piecemeal suggestions regarding these duties, and can be taken independently from the arguments of the later sections. 
But groups' duties are not identical to the membership duties they imply. In particular, I argued that groups' duties reliably to produce multilateralism are not identical to a collection of membership duties. While the relation between groups' duties and membership duties is not an identity relation, there is an important modal relation between the two: there is a failure of membership duties whenever there is a failure of group duties.

\section{Works Referenced}

Bliss, Ricki and Kelly Trogdon. 2016. "Metaphysical Grounding." The Stanford Encyclopedia of Philosophy.

Brennan, Geoff \& Nicholas Southwood, "Feasibility in Action and Attitude," T. RonnowRasmussen, B. Petersson, J. Jonefsson, D. Egonsson (eds.), Hommage a Wlodek: Philosophical Papers Dedicated to Wlodek Rabinowicz, online only, 2007, $<$ www.fil.lu.se/hommageawlodek $>$

Björnsson, Gunnar. 2014. "Essentially Shared Obligations." Midwest Studies in Philosophy 38(1), 103-120.

Collins, Stephanie. 2013. "Collectives' Duties and Collectivization Duties." Australasian Journal of Philosophy 91(2), 231-248.

Copp, David. 2007. “The Collective Moral Autonomy Thesis.” Journal of Social Philosophy 38(3), 369-388.

Copp, David. 2012. "The Collective Moral Autonomy Thesis: Reply to Ludwig and Miller," Journal of Social Philosophy 43(1), 78-95.

French, Peter A. 1979. "The Corporation as a Moral Person." American Philosophical Quarterly 16(3), 207-215.

French, Peter. 1984. Collective and Corporate Responsibility. New York: Columbia University Press. 
Hindriks, Frank. 2009. "Corporate Responsibility and Judgement Aggregation.” Economics and Philosophy 25, 161-177.

Isaacs, Tracy. 2011. Moral Responsibility in Collective Contexts. Oxford: Oxford University Press.

Jackson, Frank and Philip Pettit. 1990. "Program Explanation: A General Perspective." Analysis 50, 107-117.

Jackson, Frank and Philip Pettit. 1992. "Structural Explanation in Social Theory." Pp. 97-132

in D. Charles \& K. Lennon (eds.), Reduction, Explanation, and Realism. Oxford: Clarendon Press.

Lawford-Smith, Holly. 2012. "The Feasibility of Collectives' Actions.” Australasian Journal of Philosophy 90(3), 453-467.

List, Christian and Peter Menzies. 2009. "Non-Reductive Physicalism and the Limits of the Exclusion Principle.” The Journal of Philosophy CVI(9), 475-502.

List, Christian and Philip Pettit. 2011. Group Agency. Oxford: Oxford University Press.

List, Christian and Kai Spiekermann. 2013. 'Methodological Individualism and Holism in Political Science: A Reconciliation.' American Political Science Review 107(4), 629643.

Mäkelä, Pekka. 2007. "Collective Agents and Moral Responsibility.” Journal of Social Philosophy 38(3), 456-468.

McLaughlin, Brian and Karen Bennett. 2014. "Supervenience." The Stanford Encyclopedia of Philosophy.

Pauer-Studer, Herlinde. 2014. “A Constitutive Account of Group Agency.” Erkenntnis 79, 1623-1639.

Pettit, Philip and Robert E. Goodin. 1986. "The Possibility of Special Duties." Canadian Journal of Philosophy 16(4), 651-676. 
Pettit, Philip. 2007a. "Responsibility Incorporated.” Ethics 117, 141-201.

Pettit, Philip. 2007b. "Rationality, Reasoning and Group Agency." dialectica 61(4), 495-519.

Rovane, Carol. 1998. The Bounds of Agency: An Essay in Revisionary Metaphysics. Princeton: Princeton University Press.

Schwenkenbecher, Anne. 2013. "Joint Duties and Global Moral Obligations." Ratio 26(3), $310-328$

Smith, Thomas. 2009. "Non-distributive Blameworthiness." Proceedings of the Aristotelian Society 109, 31-60.

Strand, Anders. 2012. "Group Agency, Responsibility, and Control.” Philosophy of the Social Sciences 43(2), 201-224.

Tahko, Tuomas E. and Jonathan E. Lowe. 2015. "Ontological Dependence." The Stanford Encyclopedia of Philosophy.

Wringe, Bill. 2016. "Collective Obligations: Their Existence, Their Explanatory Power, and their Supervenience on the Obligations of Individuals." European Journal of Philosophy 24(4), 472-97.

Zoller, David J. 2014. "Distributing Collective Moral Responsibility to Group Members." Journal of Social Philosophy 45(4), 478-497. 